\title{
Microcephalic primordial dwarfism, Montreal type
}

INSERM

\section{Source}

INSERM. (1999). Orphanet: an online rare disease and orphan drug data base.

Microcephalic primordial dwarfism, Montreal type. ORPHA:2617

Microcephalic primordial dwarfism, Montreal type is a rare, genetic multiple congenital anomalies/dysmorphic syndrome characterized by severe short stature and craniofacial dysmorphism (microcephaly, narrow face with flat cheeks, ptosis, prominent nose with a convex ridge, low-set ears with small or absent lobes, high-arched/cleft palate, micrognathia), associated with premature graying and loss of scalp hair, redundant, dry and wrinkled skin of the palms, premature senility and varying deg rees of intellectual disability. Cryptorchidism and skeletal anomalies may also be observed. There have been no further descriptions in the literature since 1970. 